\title{
Biochemical analysis and scanning force microscopy reveal productive and nonproductive ADAR2 binding to RNA substrates
}

YVONNE KLAUE, ${ }^{1}$ ANNIKA M. KÄLLMAN, ${ }^{2}$ MICHAEL BONIN, ${ }^{1}$ WOLFGANG NELLEN, ${ }^{1}$ and MARIE ÖHMAN ${ }^{2}$

${ }^{1}$ Department of Genetics and CINSaT, University of Kassel, 34132 Kassel, Germany ${ }^{3}$

${ }^{2}$ Department of Molecular Biology \& Functional Genomics, University of Stockholm, SE-106 91 Stockholm, Sweden ${ }^{3}$

\begin{abstract}
Scanning force microscopy (SFM) can be used to image biomolecules at high resolution. Here we demonstrate that singlemolecule analysis by SFM complements biochemical data on RNA protein binding and can provide information that cannot be obtained by the usual biochemical methods. We have used this method to study the interaction between the RNA editing enzyme ADAR2 and RNA transcripts containing selective and nonselective editing sites. The natural selectively edited R/G site from glutamate receptor subunit B (GluR-B) was inserted into an RNA backbone molecule consisting of a completely doublestranded (ds) central part and incompletely paired ends derived from potato spindle tuber viroid (PSTVd). This molecule was efficiently edited at the R/G site, but promiscuous editing occurred at nonselective sites in the completely double-stranded region. The construct was also used to analyze binding of ADAR2 to wild-type and modified R/G editing sites in relation to binding at other nonselectively edited sites. Editing analysis together with SFM allow us to differentiate between binding and enzymatic activity. ADAR2 has been reported to have a general affinity to dsRNA. However, we show that there is a prominent bias for stable binding at sites selectively edited over other edited sites. On the other hand, promiscuous editing at nonselective sites apparently results from transient binding of the enzyme to the substrate. Furthermore, we find distinct sites with nonproductive binding of the enzyme.
\end{abstract}

Keywords: SFM; adenosine deamination; RNA-binding protein; double-stranded RNA; RNA editing; ADAR

\section{INTRODUCTION}

Adenosine deaminase that acts on RNA (ADAR) is a double-stranded RNA (dsRNA) binding enzyme that converts adenosine (A) to inosine (I) within structured RNA (for reviews, see Gerber and Keller 2001; Keegan et al. 2001). Two functional ADAR enzymes that share a common modular domain organization, ADAR1 and ADAR2, have been characterized in mammals. These enzymes recognize the double-stranded structure formed by the editing site and a complementary sequence, rather than a consensus sequence. What appears to be promiscuous deamination, in which as much as $30 \%$ of the adenosines can be edited, has been seen in the context of long stretches of completely base-paired RNA molecules of noncoding RNA (Morse and Bass 1999; Morse et al. 2002). Selective editing of specific

\footnotetext{
${ }^{3}$ These laboratories contributed equally to this work.

Reprint requests to: Marie Öhman, Department of Molecular Biology \& Functional Genomics, University of Stockholm, SE-106 91 Stockholm, Sweden; e-mail: marie.ohman@molbio.su.se; fax: 468166488.

Article and publication are at http://www.rnajournal.org/cgi/doi/ $10.1261 /$ rna.2167603.
}

sites has been found in substrates where base-paired regions are interrupted by mismatches or loops. The editing activity has been detected in many metazoans, but a relatively small number of substrates that possess site-selective editing has been found. In most of these cases, editing of a single adenosine changes the coding capacity of a pre-mRNA and results in an altered protein with properties different from the one encoded by the nonedited RNA. The editing event causes a functional A-to-G replacement because inosine is translated as guanosine. Site-selective A-to-I editing has mainly been found in pre-mRNAs encoding neurotransmitter receptors in mammals and Drosophila melanogaster (Sommer et al. 1991; Lomeli et al. 1994; Burns et al. 1997; Palladino et al. 2000). The best-understood example of RNA editing by adenosine deamination occurrs in the premRNA of mammalian ionotropic AMPA ( $\alpha$-amino-3-hydroxy-5-methyl-4-isoxazolepropionic acid) glutamate receptor subunits (GluRs) (for review, see Seeburg et al. 1998). The pre-mRNA of the GluR-B subunit is edited at two sites, $\mathrm{Q} / \mathrm{R}$ and $\mathrm{R} / \mathrm{G}$. The $\mathrm{R} / \mathrm{G}$ site, located in an arginine codon, is converted to encode for glycine after editing. Editing at the $\mathrm{R} / \mathrm{G}$ site is developmentally regulated, changing 
the gating kinetics of the receptor (Seeburg et al. 1998). ADAR2 efficiently deaminates the R/G stem-loop of the GluR-B pre-mRNA in vitro (Melcher et al. 1996; O'Connell et al. 1997; Öhman et al. 2000). The enzyme has two double-stranded RNA binding motifs (dsRBMs) and a Cterminal catalytic deamination domain. The dsRBMs have been found in a variety of other functionally diverse proteins such as helicases, kinases, and endoribonucleases (for review, see Fierro-Monti and Mathews 2000). Common to all these proteins are that they bind highly structured and completely double-stranded RNA (dsRNA) with little sequence specificity. Recent studies indicate that the edited base is flipped out of the duplex during the modification process (Stephens et al. 2000). Furthermore, it has been suggested that the RNA binding domain assists the baseflipping by increasing the conformational flexibility of the nucleotides opposite to the edited site (Yi-Brunozzi et al. 2001).

To better understand what determines selective A-to-I editing, we have examined ADAR2 binding to single molecules of highly structured RNA using scanning force microscopy (SFM). We and others have previously used SFM to analyze protein-nucleic acid interactions; for example, Hansma et al. (1999) performed a functional analysis of polymerases on their respective templates by SFM; Herbert et al. (1998) showed that the $\mathrm{z}-\alpha$ domain of ADAR1 binds to Z-DNA; Kasas et al. (1997) were able to monitor the dynamics of Escherichia coli RNA polymerase in the SFM; and we (Bonin et al. 2000) have determined preferential binding sites of a protein on dsRNA.

The RNA molecule used in this study contains both a region subjected to siteselective editing and sections that allow promiscuous, nonselective editing. Using this target molecule, it was possible to determine and quantify, editing at the selective $R / G$ editing site in relation to nonselective editing within the same molecule. In addition, we have analyzed ADAR2 binding independent of editing by scanning force microscopy (SFM). By using SFM we demonstrate, in a unique way, that there is a difference in binding for a selectively edited site and a nonselective editing sites. Furthermore, a correlation between efficiency of editing and selective binding could be seen.

\section{RESULTS}

The RNA molecule used in the experiments described here can be divided into three parts; one part containing the specific $R / G$ editing site derived from the glutamate receptor pre-mRNA; sec- ondly, a long region of completely base-paired sequence that is a target for promiscuous editing; and a third part of the RNA that is double-stranded with interruptions of bulges and loops but does not contain a specific editing site (Fig. 1). Apart from the wild-type R/G stem-loop, two mutants were used in this analysis. In the C42U46 mutant sequence, two point mutations changed an unpaired $\mathrm{G}-\mathrm{G}$ and $\mathrm{A}-\mathrm{C}$ to a $\mathrm{G}-\mathrm{C}$ and $\mathrm{A}-\mathrm{U}$ Watson-Crick base pair, closing two loops in the stem. The other mutant (G56) has the unpaired $\mathrm{C}$ exchanged for a $\mathrm{G}$ residue opposite the editing site. Short RNAs containing the wild-type and C42U46 sequences have previously been investigated by editing assays, gel mobility shift, and footprinting assays (Öhman et al. 2000). In this investigation, ADAR2 displayed no apparent difference in binding between wild-type and mutant RNA. However, the editing efficiency of the RNA decrease dramatically in the order wild type $>$ C42U46 $>$ G56 (see also Fig. 5 below and Table 1). According to the footprinting data, the association of the protein to the RNA was less pronounced in the C42U46 mutant than in the wild type (Öhman et al. 2000). The R/G stem-loops, wild type and mutants, were inserted into the gus-PSTVd backbone (Fig. 1; Bonin et al. 2001). This backbone RNA was specifically designed for RNA binding proteins, allowing a comparison between selective and promiscuous binding. The transcripts of the backbone RNA and the gus-PSTVd-R/G 75 were used in gel mobility shift assays (Fig. 2A,B). No significant difference in protein binding was detected by this method: the empty backbone bound ADAR2 with approximately equal

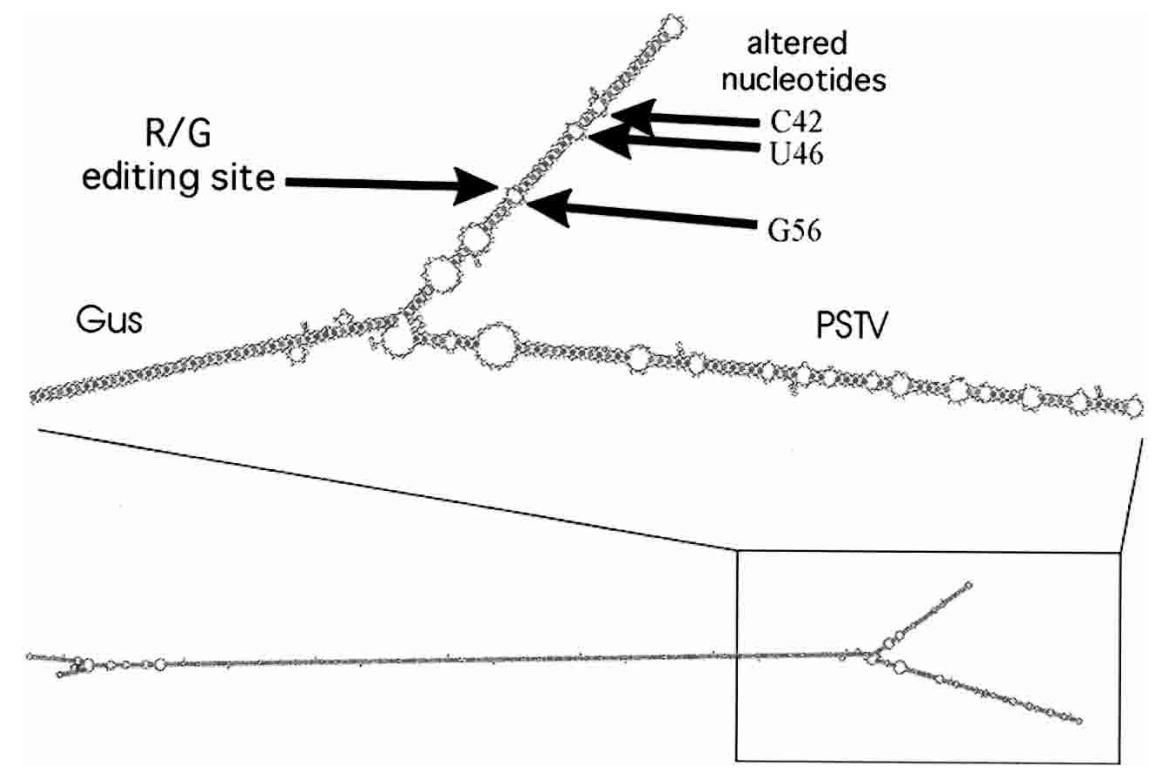

FIGURE 1. Structure of the gus-PSTVd RNA molecule with the inserted R/G stem-loop. The enlargement shows the bifurcation with the R/G stem-loop on top. Mutations in the G56 and C42U46 variants are indicated by arrows. The gus and PSTVd parts are indicated. The backbone alone displays a straight rod in $\mathrm{m}$-fold (data not shown; see Bonin et al. 2001). With the insertion of the GluR-B R/G sequence, 9 nt of the backbone $5^{\prime}$ and $15 \mathrm{nt} 3^{\prime}$ of the insert are included in the stem-loop structure. The size of the chimeric RNA is $1007 \mathrm{nt}$. 
TABLE 1. ADAR2 binding and editing of gus-PSTVd RNA constructs

\begin{tabular}{lccccc}
\hline & $\begin{array}{c}\text { Binding to } \\
\text { R/G stem-loop }\end{array}$ & $\begin{array}{c}\text { Binding to } \\
\text { segment 1 }\end{array}$ & $\begin{array}{c}\text { Binding to backbone } \\
\text { (not segment 1) }\end{array}$ & $\begin{array}{c}\text { Editing specifically } \\
\text { at R/G site }\end{array}$ & $\begin{array}{c}\text { Number of } \\
\text { nonselective editing sites }^{\text {b }}\end{array}$ \\
\hline R/G wt & $94 \%$ & $4 \%$ & $2 \%$ & $86 \%$ & 15 \\
C42U46 & $83 \%$ & $12 \%$ & $5 \%$ & ND & ND \\
G56 & $67 \%$ & $22 \%$ & $11 \%$ & $35 \%$ & 17 \\
\hline
\end{tabular}

'Binding to segment 1 is listed separately because this may be enhanced by the presence of the $5^{\prime}$ and $3^{\prime}$ ends of the molecule in this region. ${ }^{b}$ For determination of nonselective editing sites, $170 \mathrm{~A}$ residues in the backbone molecule were analyzed.

(ND) Not determined.

efficiency as the RNA with the inserted R/G stem-loop. To ensure that the shift was not caused by conformational changes due to editing (a less double-stranded character of the substrate), the gus-PSTVd RNA was treated with phenol to remove the ADAR2 protein after the binding. This RNA (post-phenol) migrated like the free RNA after phenol treat-

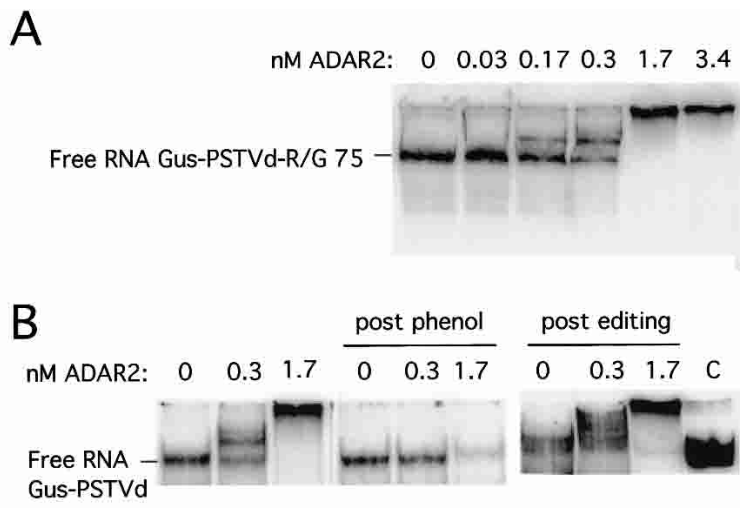

\section{C}

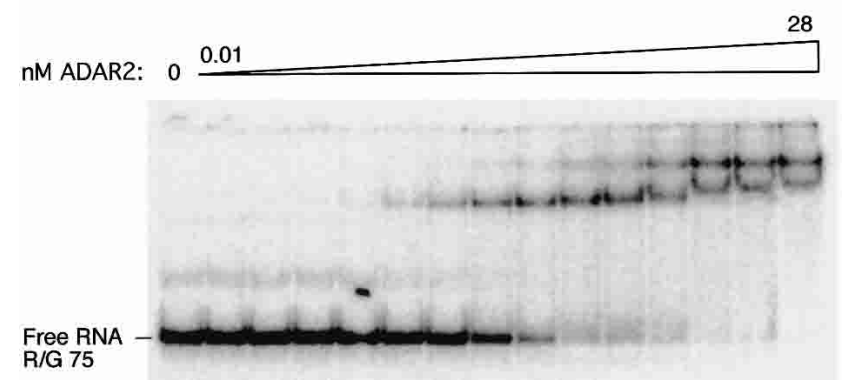

FIGURE 2. Gel mobility shift (GMS) assay with gus-PSTVd-substrates and with the 75-nt R/G site stem-loop structure. (A) GMS assay with gus-PSTVd-R/G75. Increasing amounts of recombinant ADAR2 were added as indicated. A shift to a higher-molecular-weight band was found at $0.17 \mathrm{nM}$ protein. (B) GMS assay with gus-PSTVd; the amount of ADAR2 added is indicated. In lanes marked as "post phenol," the samples were treated with phenol after protein binding (see Materials and Methods). Lanes marked as "post editing" indicate an editing assay prior to the binding assay. (Lane $C$ ) A control with nonedited free RNA. (C) GMS assay with a 75-nt-long R/G site stemloop structure. Increasing amounts of recombinant ADAR2 were added as indicated. ment, indicating that the shift was caused by protein binding. A slight shift observed at $1.7 \mathrm{nM}$ ADAR2 post-phenol treatment probably indicates slower migration because of editing. As previously seen, the short substrate containing only the R/G stem-loop exhibited two defined complex bands (Fig. 2C), which have been suggested to represent binding of protein monomers and dimers (Jaikaran et al. 2002).

In scanning force microscopy, the gus-PSTVd substrates displayed a structure resembling that predicted by $\mathrm{m}$-fold (Zuker 2000). The backbone alone appeared like a rigid rod (Bonin et al. 2001), whereas insertion of the editing sites resulted in the expected asymmetric branching that allow an orientation of the molecule (see Fig. 1). The three different target molecules were used to determine relative protein binding to the wild type and mutated $\mathrm{R} / \mathrm{G}$ binding sites in respect to the backbone. As described previously (Bonin et al. 2001), the 130-nm-long RNA molecule was subdivided into 10 sections of $13 \mathrm{~nm}$ each. Segments 1 and 2 as well as 8 to 10 contain the partially double-stranded PSTVd RNA, whereas segments 3 to 7 contained the completely paired gus RNA. The R/G stem-loop structure was located in segment 8 . ADAR2 showed an average diameter of $13 \mathrm{~nm}$ and an average height of $1 \mathrm{~nm}$ (but see below). Bound molecules could thus be assigned to a specific section. As discussed below, it was not possible to determine absolute binding (i.e., the ratio of free protein to RNA-associated protein) in a meaningful way because it appeared that free protein was preferentially lost in the washing steps. Figure 3 shows representative SFM images of the backbone molecule and of gus-PSTVd-R/G75 incubated with ADAR2. The rod-shaped backbone molecule (Fig. 3A) is symmetrical, and an orientation cannot be determined. With gus-PSTVd-R/G75, the bifurcation of the RNA is readily detectable (Fig. 3B), especially in free RNA molecules. In many cases it seems that the stem-loop structure is covered or condensed by ADAR2 binding.

In Figure 4, the relative binding frequencies of ADAR2 are shown for the backbone gus-PSTVd and the three molecules containing the R/G stem-loop variants. The backbone alone was not oriented; the bottom-left end of the RNA in the SFM image was arbitrarily assigned to segment 1 . This resulted in apparently symmetric binding frequen- 
A
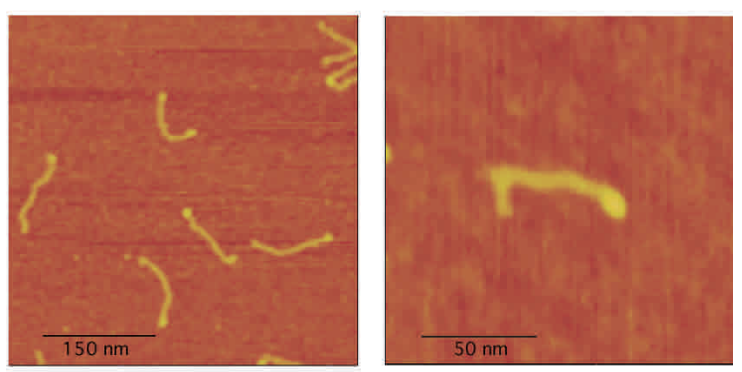

B

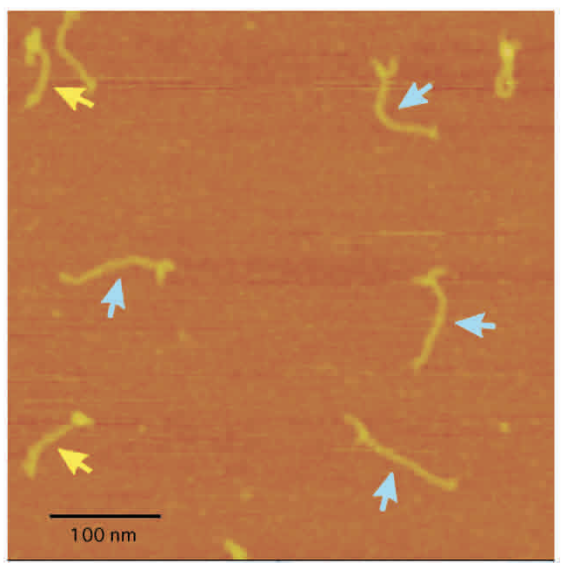

FIGURE 3. SFM images of ADAR2 binding to different substrates. (A) SFM image of gus-PSTVd backbone molecules with bound ADAR2 proteins. (Right panel) A single molecule is enlarged. Protein binding can be readily seen on the right end of the RNA. (B) SFM image of gus-PSTVd-R/G75 molecules with bound ADAR2 proteins. Note the bifurcation of the RNA, which was used to determine the orientation of the molecule. Yellow arrows indicate RNAs with ADAR2 bound to the editing stem-loop; blue arrows indicate RNAs without bound ADAR2. Note that in all images the background of unbound protein is very low. Images show selected frames.

cies along the molecule (Fig. 4A). From this graph we could not conclude if one or both ends of the PSTVd part had a binding preference for ADAR (but see below). However, the double-stranded gus RNA displayed very limited binding of the protein: only a few molecules were found on segments 3-7. A gel mobility shift assay was done to ensure that the limited binding shown by SFM was not due to the fact that editing in the double-stranded region of the backbone RNA had made the substrate too single stranded by I:U mismatches to be bound by ADAR2. Pre-edited backbone gusPSTVd RNA was shifted by ADAR2 approximately as well as nonedited RNA, indicating that the partially modified substrate could still bind the protein efficiently (Fig. 2B, right panel).

When the R/G editing substrate was introduced into segment 8 , this was in all cases the preferential binding site for the enzyme. Binding to other parts of the backbone was marginal and mostly restricted to the distal end (segment
1). We therefore concluded that most of the end binding to the backbone molecule without a selectively edited site also occurred in segment 1 . In substrates containing the wildtype $\mathrm{R} / \mathrm{G}$ stem-loop, $94 \%$ of the protein molecules were found at the selective R/G editing site; with the C42U46 mutations this was reduced to $83 \%$, whereas the G56 mutant could only recruit $67 \%$ of ADAR2. Consequently, binding to the backbone increased. This was not only because of the known preferential binding to the $5^{\prime}$ and $3^{\prime}$ ends located in segment 1 (see also Discussion), but also because of an overall increased binding: the percentage of enzyme bound to internal segments (excluding segment 1) increased from $2 \%(\mathrm{R} / \mathrm{G}$ wild type) to $5 \%$ (C42U46) to $11 \%$ (G56; see also Table 1). Binding to the backbone was low and therefore statistically difficult to evaluate, but there was no obvious preference for either dsRNA in the gus section or partially unpaired RNA in the PSTVd section (except for segment 1).

An analysis of the in vitro editing efficiency at the R/G site in gus-PSTVd constructs was made using limited primer extension. The molecule with the wild-type R/G sequence showed an efficient $\mathrm{R} / \mathrm{G}$ editing of $86 \%$, and introduction of the G56 mutation decreased editing to 35\% (Fig. 5). Editing of the wild-type R/G site agreed with the binding at segment 8 , including the $\mathrm{R} / \mathrm{G}$ stem-loop. However, the editing efficiency of the mutated $R / G$ sites appeared quantitatively lower than the observed ADAR2 binding at the respective sites.

To detect nonselective editing by ADAR2 and to be able to compare binding with editing in the same molecules, the substrates used in the SFM analysis were incubated with ADAR2, amplified by reverse transcriptase, followed by a polymerase chain reaction (RT-PCR), and then sequenced. Adenosine-to-inosine modifications were determined by either heterogeneous $A$ and $G$ peaks or single $G$ peaks on the electropherogram after sequencing. Nonselective editing was detected in segments 3-7 (Table 2). In this area the gus RNA is completely double-stranded, and promiscuous Ato-I editing would be expected. However, binding to these segments was infrequent. In contrast, no editing was found in the only partially double-stranded PSTVd sections of the backbone. Segment 1 showed the highest nonselective binding preference in the SFM images; however, no editing at all was detected in this region. Sites of nonselective editing were compared between the wild-type R/G gus-PSTVd transcript, the G56 mutant, and the backbone gus-PSTVd sequence alone. The editing pattern was very similar in the three transcripts, but by using this method the efficiency of editing at individual sites is difficult to determine accurately.

\section{DISCUSSION}

To investigate the structural requirements for ADAR editing, most studies have used glutamate receptor pre-mRNA 
A

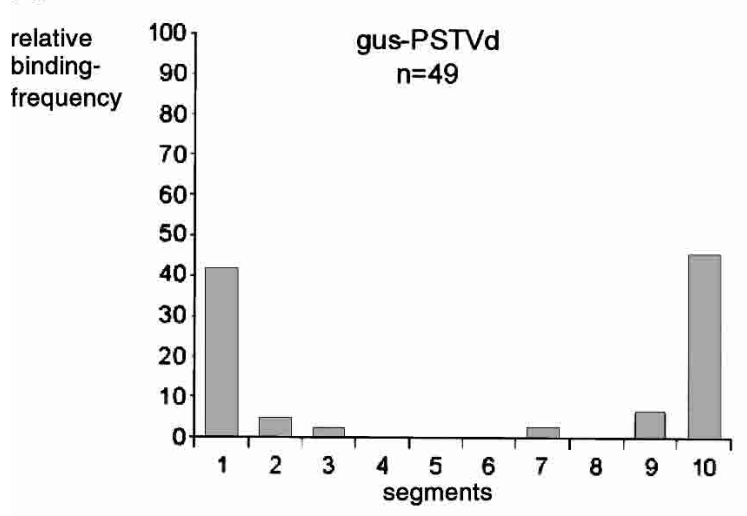

C

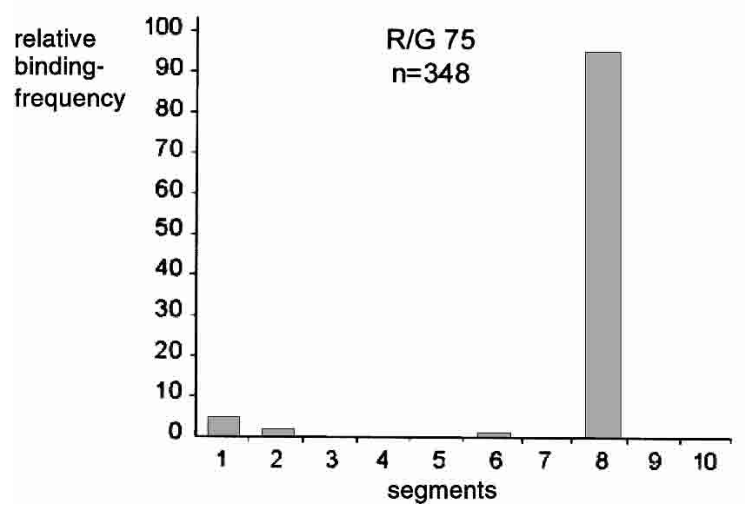

B

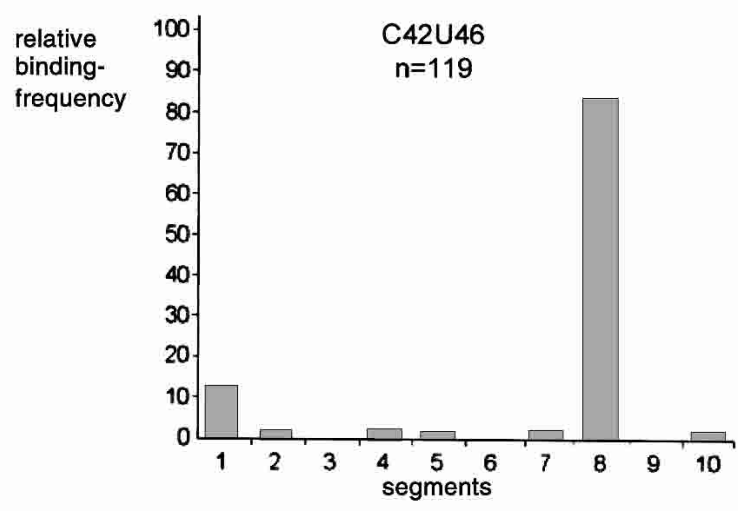

D

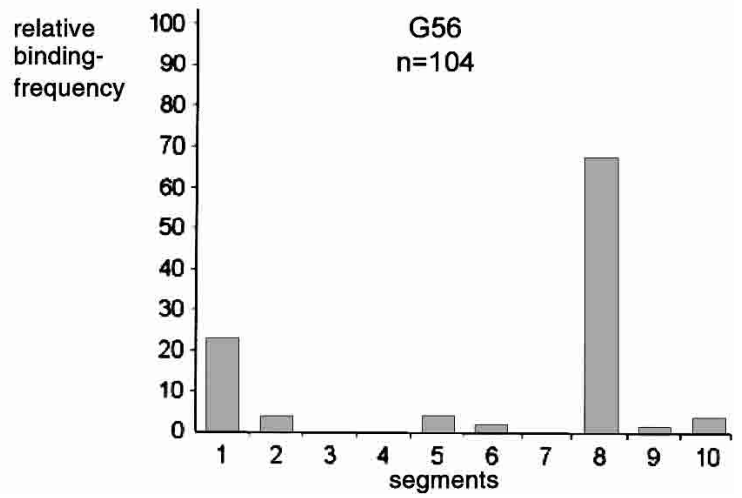

FIGURE 4. Distribution of ADAR2 binding on the different target molecules. (A) Binding to the gus-PSTVd backbone RNA. The orientation of the molecule was arbitrarily determined (see Materials and Methods), therefore the distribution of binding appears symmetrical. ADAR2 binding to the backbone $(B)$ with the R/G 75 (wild-type) stem-loop inserted, $(C)$ with the C42U46 stem-loop inserted, and $(D)$ with the G56 point mutation stem-loop inserted. $(B-D)$ The orientation was unambiguously determined by the bifurcation on the right end of the molecule (Fig. 1). Bound protein was assigned to one of 10 segments (numbered from left to right) of the RNA molecule. Except for two cases, only one protein was bound to the RNA. ( $n$ ) Number of RNA molecules examined.

with mutated and wild-type sequence to compare binding and editing efficiency. However, as exemplified in this paper, this neglects the following points: First, editing and binding are separate events; a site may very well be recognized for binding but still be edited with no or very low efficiency. Second, the enzyme is forced to a single substrate, and there is no competition with potential binding sites on other substrates. This is particularly important because ADAR2 apparently can bind and edit any completely double-stranded RNA.

To determine binding and editing requirements in a large molecule containing both a genuine editing site and sequence with no known editing sites, we have used the backbone gus-PSTVd RNA sequence fused to the sequence of the selectively edited R/G site of GluR-B pre-mRNA. In a unique way, the competition between ADAR2 binding to selectively and promiscuously edited sites can be analyzed by SFM. We show that $>90 \%$ of the molecules preferentially bind to segment 8 , where the wild-type R/G site is situated (Fig. 4B). This implies that although ADAR2 binds and edits any double-stranded RNA, the binding to selectively edited sites is more frequent. It cannot, however, be determined if the observed binding occurs on the substrate (nonedited site) or the product (edited site) because the binding affinities of these molecules are very similar (Fig. 2B; Öhman et al. 2000). Binding of the R/G stem-loop determined by SFM correlated well with selective R/G editing. When the efficiency of selective editing was decreased by mutations in the vicinity of the R/G site, binding was less prominent. With the mutations, an increased binding to the first segment of all RNA molecules was observed. We have previously shown that the ends of dsRNA are preferential binding sites for different proteins with affinity to RNA (Bonin et al. 2000, 2001). Increased binding to segment 1 (shown in Fig. 4B-D) might therefore be explained by the location of the $5^{\prime}$ and $3^{\prime}$ ends of the RNA in this region. No A-to-I editing at all was observed in this area, indicating that the increased binding observed in this region is nonproductive. The experiments shown in Figure 4 neglected the absolute affinity of the protein for the RNA. One could 
TABLE 2. Nonselective editing of backbone gus-PSTVd RNA constructs

\begin{tabular}{|c|c|c|c|c|c|c|c|c|c|c|}
\hline & \multicolumn{10}{|c|}{ Segment number } \\
\hline & 1 & 2 & 3 & 4 & 5 & 6 & 7 & $8 \mathrm{~L}$ & 9 & 10 \\
\hline \multicolumn{11}{|l|}{ gus-PSTV backbone substrate } \\
\hline No. edited sites & 0 & 0 & 2 & 1 & 2 & 5 & 6 & 0 & 0 & 0 \\
\hline Total no. of As analyzed & 12 & 25 & 21 & 15 & 21 & 20 & 21 & 14 & 18 & 3 \\
\hline Percent edited As & - & - & 10 & 7 & 10 & 25 & 29 & - & - & - \\
\hline \multicolumn{11}{|l|}{ Wild-type R/G substrate } \\
\hline No. edited sites & 0 & 0 & 2 & 1 & 2 & 5 & 5 & 0 & 0 & 0 \\
\hline Total no. of As analyzed & 12 & 25 & 21 & 15 & 21 & 20 & 21 & 14 & 18 & 3 \\
\hline Percent edited As & - & - & 10 & 7 & 10 & 25 & 24 & - & - & - \\
\hline \multicolumn{11}{|l|}{ G56 mutant substrate } \\
\hline No. edited sites & 0 & 0 & 3 & 1 & 2 & 5 & 6 & 0 & 0 & 0 \\
\hline Total no. of As analyzed & 12 & 25 & 21 & 15 & 21 & 20 & 21 & 14 & 18 & 3 \\
\hline Percent edited As & - & - & 14 & 7 & 10 & 25 & 29 & - & - & 一 \\
\hline
\end{tabular}

assume that with molecules containing low-affinity binding sites, the amount of free enzyme would be larger. However, it turned out to be difficult to test this experimentally because we have no means to determine if the RNA, the free protein, or the complex has a higher affinity to the mica surface and preferentially remains attached after the washing step in the preparation of the samples. Experiments using different ADAR2 concentrations (data not shown) indicate that unbound protein is more easily washed off. Alternatively, ADAR2 may form dimers at higher concentrations, which cannot be unambiguously distinguished from monomers. We observed a distribution of protein height from $0.5 \mathrm{~nm}$ to $2.5 \mathrm{~nm}$ with a broad maximum from $0.6 \mathrm{~nm}$ to $1.4 \mathrm{~nm}$, but a bimodal distribution, indicative for monomers and dimers, was statistically not significant (data

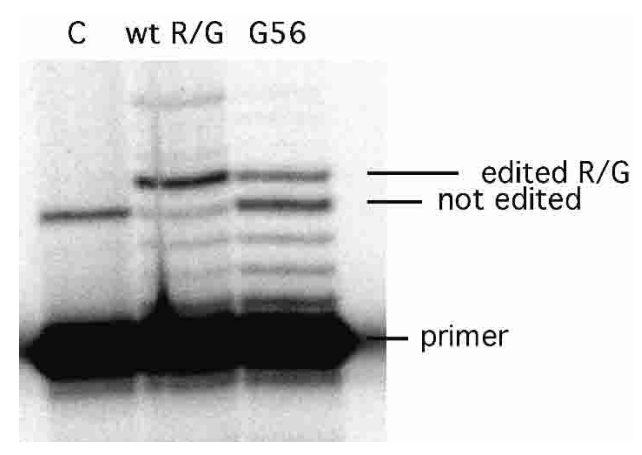

FIGURE 5. Editing at the R/G site in the wild-type and G56 mutant substrates. A limited primer-extension assay was used to monitor the $\mathrm{R} / \mathrm{G}$ site after incubation without rADAR2 (C) or with rADAR2. The assay was performed on the wild-type (wt R/G) and the G56 mutant (G56) substrates. Primer extension was done in the presence of ddT so that reverse transcriptase terminated at the $\mathrm{R} / \mathrm{G}$ site for nonedited molecules and continued to the next adenosine if the R/G was edited. Editing efficiency was calculated as described previously in Öhman et al. (2000). not shown). It appears likely that ADAR2 has an asymmetric shape, and different positioning on the surface obscures the detection of distinct dimers. However, the overall increase in the height of the protein particles with increasing protein concentrations indicated dimerization rather than nonspecific aggregation, because we never observed large complexes even at the highest protein concentrations. This is in agreement with the observation in gel mobility assays that are indicative for a stepwise formation of a monomer and then a dimer at an editing site (see Fig. 2C; Jaikaran et al. 2002).

In the experiments presented here, on average $50 \%$ of the RNA molecules exhibited binding to the enzyme. Interestingly, even with fourfold higher concentrations of protein, RNA molecules with more than one ADAR molecule (or dimer) attached were rarely found. With a total of almost 1000 RNA-protein complexes evaluated in this study, only two RNAs show binding at two sites (data not shown). It therefore seems that binding of one enzyme inhibits the entry of a second one even over a large distance.

Site-selective editing at the R/G site was shown to correlate with the binding observed in the SFM analysis. This indicates that site-selective binding leads to productive editing. However, nonselective editing of the transcripts does not correlate with binding. For example, in the completely double-stranded region of segment 7 , a high extent of nonselective editing was detected at several adenosines, but few ADAR molecules were found to bind to this segment. On the contrary, in segment 1 , but also in segments 2,9 , and 10 , significant binding in the absence of editing was observed. These are surprising examples of nonproductive binding. In summary, we can distinguish three types of binding/editing sites: (1) the cognate editing sites, where binding and editing correlate; (2) promiscuous hit-and-run editing sites, where little binding but significant editing is observed; and 
(3) nonproductive binding sites, where no editing is found even though significant binding is detected. Particularly the hit-and-run editing sites would pose a problem in vivo and result in misediting, which may not be tolerated by an organism. ADAR2 readily recognizes specific editing sites, and thus a guidance to such sequences appears not to be necessary. It would rather be required to implement a mechanism to inhibit promiscuous editing at other sites. Given that binding to nonselective sites appears to be transient, one could envision a cofactor that further destabilizes interactions with noncognate sequences and thus avoids misediting. It should be noted that binding observed by SFM does not necessarily reflect the affinity of the protein to a substrate: the off-rate that is apparently different for selective and nonselective sites is not taken into consideration in this analysis. Another explanation for the apparently increased binding to the backbone in the mutated substrates could be that the enzyme actually enters the RNA molecule at a more or less defined site in vitro and then scans for an appropriate editing site. With no such site available (or a weak editing site as in the G56 mutant), the SFM snapshot would show more randomly distributed, scanning proteins in addition to those attached to preferential sites like G56 or the molecule ends in segment 1 .

Our analysis demonstrates the power of the SFM-biochemistry combination in understanding molecular interactions: the finding of productive, nonproductive, and hitand-run ADAR binding sites provides new views on editing by ADAR2 and may open new ways to investigate the question of how misediting is avoided in vivo.

\section{MATERIALS AND METHODS}

\section{Construction of vectors for in vitro transcription}

Complementary single-stranded oligonucleotides were synthesized by Life Technologies. The following synthetic oligonucleotides with the sequence $5^{\prime}$ to $3^{\prime}$ were used: R/G75, GGATCCTCATT AAGGTGGGTGAATAGTATAACAATGTGCTCAATGTTGTTAT AGTATCCCACCTACCCTGATG; C42U46, GGATCCTCATTAA GGTGGGTGGAATGATATAACAATGTGCTCAATGTTGTTATA CTATTCCACCTACCCTGATG; G56, GGATCCTCATTAAGGTG GGTGGAATAGTATAACAATGTGCTCAATGTTGTTATAGTAT CCCACCTACCGTGATG.

The complementary oligonucleotides were annealed and 5'phosphorylated with T4 polynucleotide kinase, according to standard procedures (Maniatis et al. 1982). The plasmid pT3T7 gusPSTVd (Bonin et al. 2001) contains a single SmaI restriction site. After restriction digestion, the plasmid was dephosphorylated with shrimp alkaline phosphatase, according to standard procedures (Maniatis et al. 1982). The annealed modified oligonucleotides were cloned into this SmaI site using T4 DNA ligase and the restriction enzyme-controlled ligation. Recombinant plasmids were transformed into E. coli DH5 $\alpha$ cells. Plasmids were selected by restriction digestion and confirmed by sequencing. The resulting constructs were the plasmids pT3T7gus-PSTVd R/G75, pT3T7gus-PSTVd C42U46, and pT3T7gus-PSTVd G56.
The gus-PSTVd R/G75, C42U46, and G56 RNAs were synthesized by in vitro transcription with T7 RNA polymerase from plasmids linearized with SalI. The RNA was purified by phenol/ chloroform extraction and ethanol precipitation.

\section{Gel mobility shift assays}

Samples for gel-retardation assays using the gus-PSTVd-constructs were prepared by incubating $170 \mathrm{pM}$ radioactively labeled RNA and $30 \mathrm{pM}-3.4 \mathrm{nM}$ ADAR2 in $10 \mathrm{mM}$ Tris- $\mathrm{HCl}$ ( $\mathrm{pH} 8.0), 25 \mathrm{mM}$ $\mathrm{KCl}, 10 \mathrm{mM} \mathrm{NaCl}, 1 \mathrm{mM} \mathrm{MgCl}$, $0.5 \mathrm{mM}$ DTT, $10 \%$ glycerol, 0.1 $\mathrm{mg} / \mathrm{mL}$ BSA, and $0.2 \mathrm{mM}$ ATP in a total volume of $15 \mu \mathrm{L}$ at room temperature for $15 \mathrm{~min}$ (Bass et al. 1994). The complexes were analyzed on a nondenaturing $5 \%$ PAGE at $4^{\circ} \mathrm{C}$ in $1 \times$ TBE for $2 \mathrm{~h}$ at $160 \mathrm{~V}$. Samples labeled "post phenol" were prepared as above but extracted with 1 volume of phenol/chloroform after ADAR2 binding. The "post editing" samples, were edited according to the ADAR editing assay (see below) prior to the gel-retardation assay described above. The gel-retardation assay for the R/G 75 stemloop structure was prepared by incubating 10 pM RNA and 15 pM-28 nM ADAR2 (described previously in Öhman et al. 2000).

\section{Preparation of samples for SFM and imaging parameters}

Mica was freshly cleaved and activated for $1 \mathrm{~min}$ in an air plasma at $0.2 \mathrm{mbar}, 600 \mathrm{~V}$, and $20 \mathrm{kHz}$. Then $300-330 \mathrm{nM}$ dsRNA was incubated with 10-75 $\mathrm{nM}$ ADAR2 in $10 \mathrm{mM}$ Tris- $\mathrm{HCl}(\mathrm{pH} 8.0)$, $25 \mathrm{mM} \mathrm{KCl}$, and $10 \mathrm{mM} \mathrm{NaCl}$ at room temperature for $2 \mathrm{~min}$. Next, $1 \mu \mathrm{L}$ of this assay was loaded onto the mica surface together with $9 \mu \mathrm{L}$ of $5 \mathrm{mM} \mathrm{MgCl}_{2}$. After $1 \mathrm{~min}$, the mica was rinsed with $1 \mathrm{~mL}$ of water and blown dry with nitrogen. Samples were scanned with Nanoscope III multimode SFM (Digital instruments) operated in the tapping mode using an $\mathrm{E}$ scanner with a $10 \times 10$ $(x, y) \times 2.5(z) \mu \mathrm{m}$ scan range. Microfabricated silicon tips with a force constant of $42 \mathrm{~N} / \mathrm{m}$ and a resonance frequency of $320 \mathrm{kHz}$ (Pointprobes, Nanosensors $\mathrm{GmbH}$ ) were used. Images were obtained in the topographic mode. Measurements were done in air (relative humidity $25 \%-60 \%)$ at room temperature $\left(18^{\circ} \mathrm{C}-27^{\circ} \mathrm{C}\right)$. Images $(512 \times 512$ pixels $)$ were taken at $1 \mathrm{~Hz}$ scanning frequency. Images were processed with Nanoscope software including operations of plane fitting and flattening. Contour length measurement was done by drawing a traverse line along the skeleton of the molecule on the screen. For quantitative analysis of ADAR2 binding to the RNA molecules, molecules were subdivided into 10 segments. Left and down in the image was arbitrarily defined as segment 1 for gus-PSTVd. RNA molecules containing an editing site could be unambiguously oriented by the bifurcation. Segment 1 was assigned to the distal end with respect to the bifurcation/ editing site. The number of ADAR2 molecules found in each segment was counted and divided by the total number of bound proteins (relative binding frequency).

\section{Protein expression}

Recombinant rat ADAR2a protein used in the binding and editing assays was expressed in Pichia pastoris (previously described in Öhman et al. 2000). 


\section{ADAR editing assays}

For editing determination by sequencing, 500 fmole of RNA was dissolved in $40 \mathrm{mM}$ Tris- $\mathrm{HCl}$ ( $\mathrm{pH} 8$ ), $5 \%$ glycerol, $25 \mathrm{mM} \mathrm{KCl}, 1.1$ $\mathrm{mM} \mathrm{MgCl}$, $1 \mathrm{mM}$ DTT, $5 \mathrm{mM}$ EDTA, $0.2 \mathrm{mM} \mathrm{ATP}$, and 0.16 $\mathrm{U} / \mu \mathrm{L}$ RNasin (Promega). Then $200 \mathrm{ng}$ of recombinant rat ADAR2 was added to a total volume of $100 \mu \mathrm{L}$ and incubated at $30^{\circ} \mathrm{C}$ for $30 \mathrm{~min}$. Edited RNA was phenol/chloroform-extracted and precipitated. Using Omniscript reverse transcriptase (QIAGEN), the edited RNA was transcribed accorded to the recommended protocol, except for the following. Because of the high degree of secondary structure, the RNA and primer mix was denatured at $65^{\circ} \mathrm{C}$ for $5 \mathrm{~min}$. Elongation incubation was prolonged to $2 \mathrm{~h}$, and the temperature was elevated to $44^{\circ} \mathrm{C}$. Using Taq DNA polymerase (QIAGEN) with the optional Q-solution for difficult templates, the cDNA was amplified in four overlapping sections. The primer sequences are available from the author. The PCR fragments were sequenced using the BigDye sequencing kit (Applied Biosystems) and run on an ABI PRISM 377 DNA Sequencer.

A limited primer extension assay was performed to determine editing at the R/G site (previously described in Öhman et al. 2000).

\section{ACKNOWLEDGMENTS}

We thank R. Kassing and E. Oesterschulze for expert advice on SFM techniques. M.B. was supported in part by a stipend from the Otto-Baun-Fonds. W.N. was funded by a ZFF grant from Kassel University. M.Ö. was funded by a grant from the Swedish research council.

The publication costs of this article were defrayed in part by payment of page charges. This article must therefore be hereby marked "advertisement" in accordance with 18 USC section 1734 solely to indicate this fact.

Received October 28, 2002; accepted March 28, 2003.

\section{REFERENCES}

Bass, B.L., Hurst, S.R., and Singer, J.D. 1994. Binding properties of newly identified Xenopus proteins containing dsRNA-binding motifs. Curr. Biol. 4: 301-314.

Bonin, M., Oberstrass, J., Lukacs, N., Ewert, K., Oesterschulze, E., Kassing, R., and Nellen, W. 2000. Determination of preferential binding sites for anti-dsRNA antibodies on double-stranded RNA by scanning force microscopy. RNA 6: 563-570.

Bonin, M., Oberstrass, J., Vogt, U., Wassenegger, M., and Nellen, W. 2001. Binding of IRE-BP to its cognate RNA sequence: SFM studies on a universal RNA backbone for the analysis of RNA-protein interaction. Biol. Chem. 382: 1157-1162.

Burns, C.M., Chu, H., Rueter, S.M., Hutchinson, L.K., Canton, H., Sanders-Bush, E., and Emeson, R.B. 1997. Regulation of serotonin2C receptor G-protein coupling by RNA editing. Nature 387: $303-$ 308.

Fierro-Monti, I. and Mathews, M.B. 2000. Proteins binding to du- plexed RNA: One motif, multiple functions. Trends Biochem. Sci. 25: $241-246$.

Gerber, A.P. and Keller, W. 2001. RNA editing by base deamination: More enzymes, more targets, new mysteries. Trends Biochem. Sci. 26: $376-384$.

Hansma, H.G., Golan, R., Hsieh, W., Daubendiek, S.L., and Kool, E.T. 1999. Polymerase activities and RNA structures in the atomic force microscope. J. Struct. Biol. 127: 240-247.

Herbert, A., Schade, M., Lowenhaupt, K., Alfken, J., Schwartz, T., Shlyakhtenko, L.S., Lyubchenko, Y.L., and Rich, A. 1998. The Z $\alpha$ domain from human ADAR1 binds to the Z-DNA conformer of many different sequences. Nucleic Acids Res. 26: 3486-3493.

Jaikaran, D.C., Collins, C.H., and MacMillan, A.M. 2002. Adenosine to inosine editing by ADAR2 requires formation of a ternary complex on the GluR-B R/G Site. J. Biol. Chem. 5: 5.

Kasas, S., Thomson, N.H., Smith, B.L., Hansma, H.G., Zhu, X., Guthold, M., Bustamante, C., Kool, E.T., Kashlev, M., and Hansma, P.K. 1997. Escherichia coli RNA polymerase activity observed using atomic force microscopy. Biochemistry 36: 461-468.

Keegan, L.P., Gallo, A., and O'Connell, M.A. 2001. The many roles of an RNA editor. Nat. Rev. Genet. 2: 869-878.

Lomeli, H., Mosbacher, J., Melcher, T., Hoger, T., Geiger, J.R., Kuner, T., Monyer, H., Higuchi, M., Bach, A., and Seeburg, P.H. 1994. Control of kinetic properties of AMPA receptor channels by nuclear RNA editing. Science 266: 1709-1713.

Maniatis, T., Fritsch, E.F., and Sambrook, J. 1982. Molecular cloning: A laboratory manual. Cold Spring Harbor Laboratory, Cold Spring Harbor, NY.

Melcher, T., Maas, S., Herb, A., Sprengel, R., Seeburg, P.H., and Higuchi, M. 1996. A mammalian RNA editing enzyme. Nature 379: 460-464.

Morse, D.P. and Bass, B.L. 1999. Long RNA hairpins that contain inosine are present in Caenorhabditis elegans poly (A) ${ }^{+}$RNA. Proc. Natl. Acad. Sci. 96: 6048-6053.

Morse, D.P., Aruscavage, P.J., and Bass, B.L. 2002. RNA hairpins in noncoding regions of human brain and Caenorhabditis elegans mRNA are edited by adenosine deaminases that act on RNA. Proc. Natl. Acad. Sci. 99: 7906-7911.

O'Connell, M.A., Gerber, A., and Keller, W. 1997. Purification of human double-stranded RNA-specific editase 1 (hRED1) involved in editing of brain glutamate receptor B pre-mRNA. J. Biol. Chem. 272: 473-478.

Öhman, M., Kallman, A.M., and Bass, B.L. 2000. In vitro analysis of the binding of ADAR2 to the pre-mRNA encoding the GluR-B R/G site. RNA 6: 687-697.

Palladino, M.J., Keegan, L.P., O'Connell, M.A., and Reenan, R.A. 2000. A-to-I pre-mRNA editing in Drosophila is primarily involved in adult nervous system function and integrity. Cell 102: 437-449.

Seeburg, P.H., Higuchi, M., and Sprengel, R. 1998. RNA editing of brain glutamate receptor channels: Mechanism and physiology. Brain Res. Brain Res. Rev. 26: 217-229.

Sommer, B., Kohler, M., Sprengel, R., and Seeburg, P.H. 1991. RNA editing in brain controls a determinant of ion flow in glutamategated channels. Cell 67: 11-19.

Stephens, O.M., Yi-Brunozzi, H.Y., and Beal, P.A. 2000. Analysis of the RNA-editing reaction of ADAR2 with structural and fluorescent analogues of the GluR-B R/G editing site. Biochemistry 39: 1224312251.

Yi-Brunozzi, H.Y., Stephens, O.M., and Beal, P.A. 2001. Conformational changes that occur during an RNA-editing adenosine deamination reaction. J. Biol. Chem. 276: 37827-37833.

Zuker, M. 2000. Calculating nucleic acid secondary structure. Curr. Opin. Struct. Biol. 10: 303-310. 

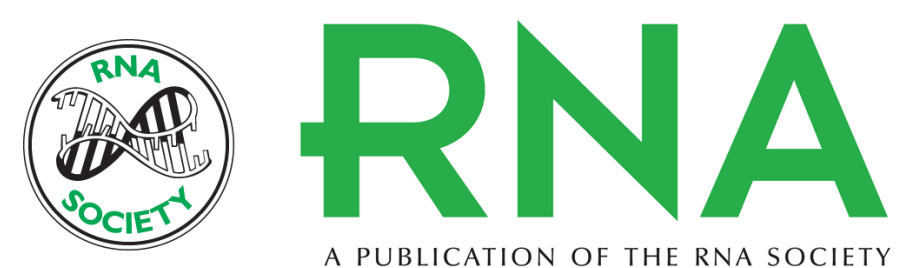

A PUBLICATION OF THE RNA SOCIETY

\section{Biochemical analysis and scanning force microscopy reveal productive and nonproductive ADAR2 binding to RNA substrates}

YVONNE KLAUE, ANNIKA M. KÄLLMAN, MICHAEL BONIN, et al.

RNA 2003 9: 839-846

References This article cites 22 articles, 7 of which can be accessed free at:

http://rnajournal.cshlp.org/content/9/7/839.full.html\#ref-list-1

\section{License}

Email Alerting Receive free email alerts when new articles cite this article - sign up in the box at Service the top right corner of the article or click here.

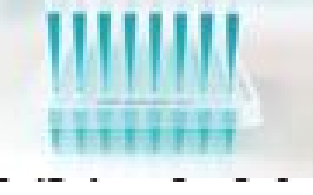

\section{Providing Precise Solutions for} your research.

To subscribe to RNA go to:

http://rnajournal.cshlp.org/subscriptions 